\title{
Identifikasi Potensi Bahaya K3 pada Tim Petugas Pemadam Kebakaran di Dinas Pemadam Kebakaran Kota Surakarta
}

\author{
Identification of Occupational Health and Safety Hazard Potential \\ in the Fire Fighting Team at the Surakarta City Fire Department
}

\author{
Chatarina Dorin Satiam Eva Jayati ${ }^{1}$, Nur Ani ${ }^{2 *}$, Triyanta ${ }^{3}$ \\ Program Studi Kesehatan Masyarakat, Universitas Veteran Bangun Nusantara Sukoharjo 1,2 \\ Rumah Sakit Umum Paru Surakarta ${ }^{3}$ \\ Email: dorinchatarina@gmail.com ${ }^{I}$ aninurk3@gmail.com
}

\begin{abstract}
Determined The research purpose was the risk analysis of Occupational Health and Safety hazards in the Surakarta City Fire Department firefighting team. This study is a qualitative descriptive. It was the approach that used the HIRA (Hazard Identification ad Risk Assessment) method. Research conducted at the Surakarta City Fire Department with the subjects of this study were firefighters. Used Data collection techniques were in-depth interviews, observation, and documentation. The data analysis technique was used as an interactive model data analysis technique, consisting of three data analysis components: data reduction, data presentation, and concluding. This results study were indicated that the highest level of risk faced by firefighters in the Surakarta City Fire Department is in the moderate category as many as ten (41.67\%) potential hazards, the high-risk level category is as much as seven $(29.17 \%)$, and two $(8.33 \%)$ potential hazards in the category of extreme risk level category. At the same time, those in the low sort were five (20.83\%) potential hazards.
\end{abstract}

Keywords: HIRA, Identification, risk analysis, Occupational Health Safety, Fire Fighting Team

\begin{abstract}
ABSTRAK
Tujuan penelitian ini adalah mengetahui analisa risiko bahaya $\mathrm{K} 3$ pada tim petugas pemadam kebakaran di Dinas Pemadam Kebakaran Kota Surakarta. Jenis penelitian ini adalah deskriptif kualitatif. Pendekatan yang digunakan dalam penelitian ini adalah dengan menggunakan metode Tools HIRA (Hazard Identification ad Risk Asessment). Penelitian yang dilaksanakan di Dinas Pemadam Kebakaran Kota Surakarta. Subyek penelitian adalah petugas pemadam kebakaran pada Dinas Pemadam Kebakaran Kota Surakarta. Teknik pengumpulan data yang digunakan adalah wawancara mendalam, observasi, dan dokumentasi. Teknik analisis data yang digunakan adalah teknik analisis data model interaktif, yang terdiri dari tiga komponen analisis data yaitu: reduksi data, penyajian data, dan penarikan kesimpulan. Hasil penelitian ini menunjukkan bahwa level risiko terbanyak yang dihadapi oleh petugas pemadam kebakaran di Dinas Pemadam Kebakaran Kota Surakarta adalah dalam kategori sedang yaitu sebanyak 10 (41,67\%) potensi bahaya, level risiko kategori tinggi sebanyak $7(29,17 \%)$ potensi bahaya, dan $2(8,33 \%)$ potensi bahaya yang masuk kategori level risiko extrem. Sedangkan yang masuk ketegori rendah sebanyak 5 $(20,83 \%)$ potensi bahaya. Berdasarkan kesimpulan tersebut diajukan saran kepada Dinas Kebakaran Kota Surakarta agar selalu melakukan perawatan terhadap Alat Pelindung Diri khususnya baju tahan api, masker pelindung wajah, dan alat bantu pernafasan untuk mengindarkan petugas pemadam kebakaran dari paparan bahaya yang disebabkan suhu tinggi dan menghisap asap kebakaran.
\end{abstract}

Kata kunci: HIRA, Identifikasi, Analisis Risiko, K3, Tim Pemadam Kebakaran

\section{PENDAHULUAN}

Kebakaran merupakan satu bahaya yang diakibatkan oleh adanya ancaman potensial berupa percikan api sejak awal terjadinya api hingga penjalaran api dan asap lalu gas yang ditimbulkan (Badan Standarisasi Nasional Indonesia, 2000). Saat terjadi kebakaran, api 
timbul sebagai reaksi proses rantai antara bahan mudah terbakar (fuel), oksigen (O2), dan panas (heat) yang sering disebut segitiga api (fire triangle). Sampai salah satu elemen pembentuk api berakhir, rangkaian proses oksidasi akan terus berlangsung, dan untuk mencegah terjadiya api, maka salah satu komponen tersebut harus dihindari/ diputus (Pratomo Setyadi dan Yola Furqaan Nanda, 2017).

Keselamatan petugas pemadam kebakaran dalam operasi pemadaman memang perlu mendapat perhatian serius. Sebab peristiwa kecelakaaan petugas pemadam kebakaran saat melakukan operasi pemadaman seringkali terjadi seperti luka-luka bahkan meninggal dunia. Namun sampai saat ini belum ada data resmi yang dikeluarkan oleh institusi pemadam kebakaran mengenai jumlah petugas pemadam kebakaran yang mengalami kecelakaan saat operasi pemadaman kebakaran (Aini, 2016).

Pemadam kebakaran merupakan pekerjaan dengan risiko tinggi berupa luka-luka dan penyakit akibat kerja yang dapat mengakibatkan cacat dan kematian. Fakta bahwa lingkungan kerja selama keadaan darurat dan tak terduga serta petugas pemadam kebakaran yang tidak siap untuk setiap kemungkinan, membutuhkan pengalaman pelatihan dan pendidikan serta pengembangan alat pelindung diri untuk melindungi petugas pemadam kebakaran dari bahaya dan risiko pekerjaannya (Andriyan, 2011).

Kewenangan umum dinas pemadam kebakaran dalam memadamkan kebakaran tercantum dalam The Fire Services Acts 1947 yang mempersyaratkan petugas pemadam kebakaran bekerja dengan efisien dan terorganisasi guna memastikan pasokan air yang mencukupi untuk memadamkan kebakaran dan memberikan hak kepada petugas pemadam kebakaran untuk memasuki gedung-gedung jika dicurigai sedang mengalami kebakaran (Andriyan, 2011).

Dinas Pemadam Kebakaran Kota Surakarta memiliki tugas yang berat dan penuh bahaya dalam penanggulangan kebakaran di Kota Surakarta dan sekitarnya. Berdasarkan data dari Dinas Pemadam Kebakaran Kota Surakarta, pada tahun 2018 terjadi 80 peristiwa kebakaran, pada tahun 2017 terjadi 78 kali peristiwa kebakaran, pada tahun 2016 terjadi 60 peristiwa kebakaran, dan 55 peristiwa kebakaran pada tahun 2015. Laporan kejadian Bidang Penyelamatan dan Penangganan Kebakaran pada tahun 2017 terdapat 78 kejadian kebakaran yang memakan kerugian sebesar Rp. 2.717.875.000,00. Berdasarkan keterangan dari Dinas Pemadam Kebakaran Kota Surakarta, penyebab terbesar terjadinya kebakaran adalah korsleting listrik dengan total 33 peristiwa dan kebocoran gas dengan total 22 peristiwa (Badan Perencanaan, Penelitian dan Pengembangan Daerah Kota Surakarta, 2018).

Kondisi wilayah Kota Surakarta tergolong padat, meningkatkan frekuensi kemungkinan terjadinya bencana kebakaran. Penanganan kebakaran di Kota Surakarta mengalami beberapa permasalahan. Permasalahan tersebut antara lain response time terhadap kebakaran serta jalan (lalu lintas) di kota Surakarta yang belum sesuai dan ketersediaan pos pemadam kebakaran dan jangkauan dari sistem hidran yang belum dapat menjangkau seluruh wilayah Kota Surakarta. Kemacetan juga menjadi penghambat proses penanggulangan kebakaran karena waktu tempuh mobil Dinas Pemadam Kebakaran untuk segera menjangkau lokasi kebakaran, sehingga meningkatkan risiko kerugian akibat kebakaran karena waktu pemadaman yang semakin lama. Sebagian besar bencana kebakaran yang terjadi di Kota Surakarta terjadi akibat hubungan arus pendek pada instalasi listrik, pembakaran sampah, maupun akibat kebocoran gas. Hal tersebut mengakibatkan kerugian seperti adanya korban dengan luka ringan hingga korban meninggal serta kerugian materi (Badan Perencanaan, Penelitian dan Pengembangan Daerah Kota Surakarta, 2018).

Kejadian kebakaran merupakan salah satu bentuk kecelakaan yang tidak dapat diprediksi sebelumnya, sehingga tim petugas pemadam kebakaran dituntut untuk selalu 
siaga ketika bertugas. Pekerjaan petugas pemadam kebakaran merupakan pekerjaan yang mengandung resiko kerja yang sangat tinggi. Resiko tim petugas pemadam kebakaran dapat dilihat dari paparan potensi resiko dan dampak resiko. Paparan resiko pada tim petugas pemadam kebakaran merupakan bahaya potensial yang meliputi bahaya fisik, bahaya kimia, bahaya listrik, bahaya mekanik dan bahaya biologi. Bahaya-bahaya tersebut dapat mengakibatkan penyakit akibat kerja (Shafwani, 2012).

Selama melakukan tugas operasionalnya, baik pemadaman kebakaran maupun penyelamatan jiwa, seorang petugas pemadam kebakaran dituntut untuk mampu mengenali jenis-jenis bahaya yang mungkin timbul pada situasi darurat. Bahaya yang dihadapi petugas pemadam kebakaran antara lain (ILO, 2000): physical hazard, chemical hazard, electrical hazard, mechanical hazard dan biological hazard. Risiko petugas pemadam kebakaran dapat dilihat dari paparan potensi risiko dan dampak risiko. Paparan risiko pada petugas pemadam kebakaran merupakan bahaya potensial yang meliputi bahaya fisik, bahaya kimia, bahaya listrik, bahaya mekanik dan bahaya biologi. Bahayabahaya tersebut dapat mengakibatkan penyakit akibat kerja (Andriyan, 2011).

Berdasarkan permasalahan di atas, maka perlu dilakukan penelitian terkait mengidentifikasi potensi bahaya K3 pada tim petugas pemadam kebakaran Kota Surakarta serta penentuan solusi dan rekomendasi terkait dengan potensi bahaya dan risiko pada petugas pemadam kebakaran Kota Surakarta guna mengurangi risiko bahaya sehingga dapat mencegah kecelakaan kerja, dari yang nearmiss hingga yang fatalOleh karena itu, peneliti ingin melakukan identifikasi potensi bahaya $\mathrm{K} 3$ pada petugas pemadam kebakaran dalam upaya pengendalian kejadian kebakaran di Dinas Pemadam Kebakaran Kota Surakarta. Tujuan penelitian ini adalah mengetahui identifikasi potensi bahaya K3 pada tim petugas pemadam kebakaran di Dinas Pemadam Kebakaran Kota surakarta tahun 2020.

\section{METODE}

Penelitian ini merupakan penelitian kualitatif dengan menggunakan metode diskriptif analitik. Peneliti menggunakan jenis penelitian kualitatif sebab peneliti ingin menggambarkan/ mendeskripsikan bagaimana identifikasi potensi bahaya K3 pada Tim Petugas Pemadam Kebakaran di Dinas Pemadam Kebakaran Kota Surakarta. Pendekatan yang digunakan dalam dalam mengidentifikasi resiko potensi bahaya K3 adalah menggunakan tools Matrik HIRA (Hazard Identification and Risk Asessment). HIRA merupakan suatu metode dan memiliki prosedur pengidentifikasi bahaya yang dapat terjadi dalam aktifitas rutin ataupun non rutin di dalam perusahaan, untuk selanjutnya dilakukan penilaian risiko dari bahaya tersebut.

Penelitian ini mengambil lokasi penelitian di Dinas Pemadam Kebakaran Kota Surakarta, dengan subyek penelitian adalah tim petugas kebakaran. Pemilihan lokasi tersebut didasarkan alasan bahwa lokasi tersebut merupakan instansi pemerintah yang bertugas melaksanakan tugas pemadaman kebakaran di Kota Surakarta. Variabel penelitian ini adalah variabel tunggal yaitu Penilaian HIRA meliputi identifikasi bahaya, penilaian risiko, analisis risiko. Subyek penelitian merupakan informan dalam penelitian ini yaitu petugas pemadam kebakaran kota Surakarta. Adapun teknik pengumpulan data yang digunakan antara lain observasi, wawancara mendalam dan dokumentasi.

Instrumen yang digunakan dalam penelitian ini adalah 1) Matrik Tabel HIRA (Hazard Identification and Risk Assessment) untuk mengidentifikasi bahaya-bahaya yang pada petugas pemadam kebakaran dalam upaya memadamkan peristiwa kebakaran di Kota Surakarta; 2) Pedoman wawancara terstruktur dan lembar observasi untuk menganalisis bahaya pada petugas pemadam kebakaran dalam upaya memadamkan peristiwa kebakaran 
di Kota Surakarta; 3) Dokumen standar operasional prosedur yang telah ditetapkan oleh Dinas Pemadam Kebakaran Kota Surakarta; dan 4) Alat-alat pencatatan dan dokumentasi.

Aktivitas dalam analisis data yaitu data reduction, data display, dan conclusion drawing/verification. Pengolahan dan analisis data yang dilakukan untuk menganalisis risiko bahaya K3 petugas pemadam kebakaran pada Dinas Pemadam Kebakaran Kota Surakarta yaitu dengan membandingkan hasil HIRA yang dibuat dengan literatur-literatur mengenai HIRA (Studi kepustakaan) dan penelitian sebelumnya.

\section{HASIL DAN PEMBAHASAN}

\section{Jenis Bahaya K3 yang Dihadapi Petugas Pemadam Kebakaran}

Berdasarkan hasil wawancara dengan petugas pemadam kebakaran Kota Surakarta, diketahui bahwa jenis bahaya yang dihadapi oleh petugas pemadam kebakaran adalah sebagai berikut:

a. Persiapan keberangkatan

1) Jatuh dari tangga atau tiang pemadam kebakaran ketika mendapatkan panggilan darurat untuk melaksanakan pemadaman kebakaran

2) Bertabrakan dengan petugas lain

3) Terpeleset saat naik ke atas mobil damkar dikarenakan terburu-buru

b. Berangkat ke lokasi

1) Jatuh dari mobil karena kecepatan tinggi dan petugas duduk di tangki

2) Kecelakaan lalu lintas

3) Pohon dan kabel listrik yang melintang jalan membahayakan petugas yang duduk di atas mobil

c. Penyiapan alat di lokasi kebakaran

1) Terbelit selang air ketika mempersiapkan selang dari pompa ke lokasi kebakaraan

2) Kerumunan warga di lokasi kebakaran mengganggu mobilitas petugas dan membahayakan warga sendiri

d. Proses pemadaman

1) Suhu udara yang panas di lokasi kebakaran yang bisa mencapai $100^{\circ} \mathrm{C}$

2) Terseret selang air yang memilki tekanan tinggi yang tersambung dengan pompa air

3) Tersengat aliran listrik

4) Menghisap asap kebakaran yang mengandung zat-zat berbahaya antara lain Karbonmonoksida (CO), Karbondioksida $\left(\mathrm{CO}_{2}\right)$, Asam Sianida $(\mathrm{HCN})$, Akrolin, Asam klorida $(\mathrm{HCl})$

5) Mata perih terkena asap dan debu

6) Terkena reruntuhan bangunan

7) Terjatuh atau terpeleset karena genangan air atau lokasi licin

8) Terbakar

9) Bekerja di ketinggian ketika melakukan pemadaman menggunakan crane

10) Ledakan bahan kimia (gas beracun)

11) Back draf (ledakan yang dihasilkan dari penyalaan serentak ketika suhu panas maksimal dan kurangnya asupan $\mathrm{O} 2$ ketika mendapatkan $\mathrm{O} 2$ terjadilah ledakan serentak

12) Terkena benda tajam seperti kaca, besi, dan serpihan benda-benda lainnya

13) Peralatan kerja yang kurang sempurna

14) Kehabisan air dalam tangki mobil damkar 
e. Kembali ke markas

1) Terjatuh dari mobil karena kelelahan dan tingkat konsentrasi yang rendah

2) Kelelahan akibat proses pemadaman yang lama

\section{Identififikasi Bahaya Petugas Pemadam Kebakaran Kota Surakarta}

Identifikasi potensi resiko bahaya $\mathrm{K} 3$, penilaian dan pengendalian risiko dipaparkan menggunakan form HIRA (Hazard Identification \& Risk Assessment). Potensi bahaya petugas pemadam kebakaran tersebut memiliki tingkat kemungkinan, keparahan, dan tingkat risiko yang berbeda-beda. Tingkat kemungkinan (probability) terjadinya risiko bahaya bagi petugas pemadam kebakaran di Dinas Pemadam Kebakaran Kota Surakarta di tampilkan dalam grafik sebagai berikut:

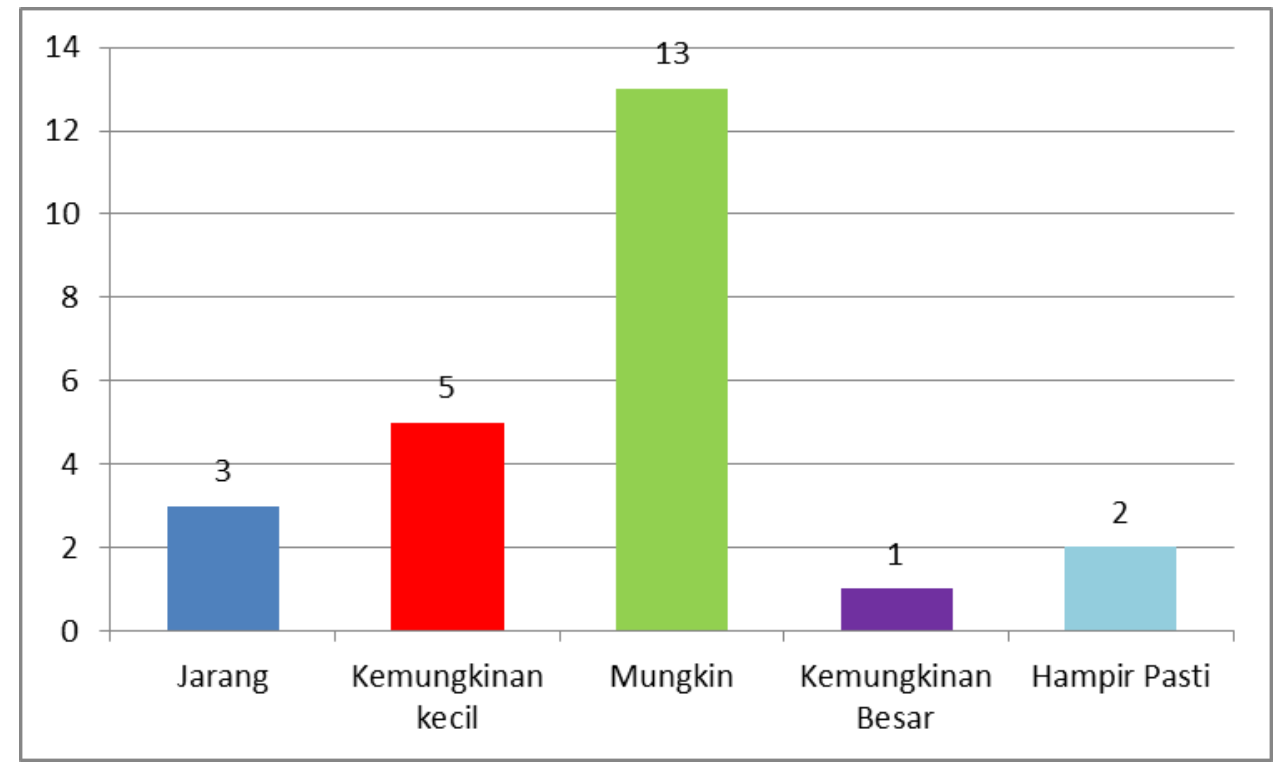

Gambar 1. Grafik Kemungkinan Terjadinya Risiko Bahaya

Grafik di atas menunjukkan bahwa tingkat kemungkinan (probability) terjadinya risiko bahaya $\mathrm{K} 3$ bagi petugas pemadam kebakaran dalam menjalankan tugasnya untuk memadamkan kebakaran sebagian besar masuk dalam level 3 (mungkin) yaitu sebanyak 13 $(54,17 \%)$ resiko bahaya. Kemungkinan terjadinya risiko bahaya K3 level 1 (jarang terjadi) sebanyak $3(12,50 \%)$ resiko bahaya, level 2 (kemungkinan kecil) sebanyak 5 (20,83\%) resiko bahaya, level 4 (kemungkinan besar) sebanyak $1(4,17 \%)$ resiko bahaya, dan level 5 (hampir pasti) sebanyak $2(8,33 \%)$ resiko bahaya.

Tingkat keparahan (severity) risiko bahaya petugas pemadam kebakaran pada Dinas Pemadam Kebakaran Kota Surakarta ditampilkan dalam grafik berikut ini: 


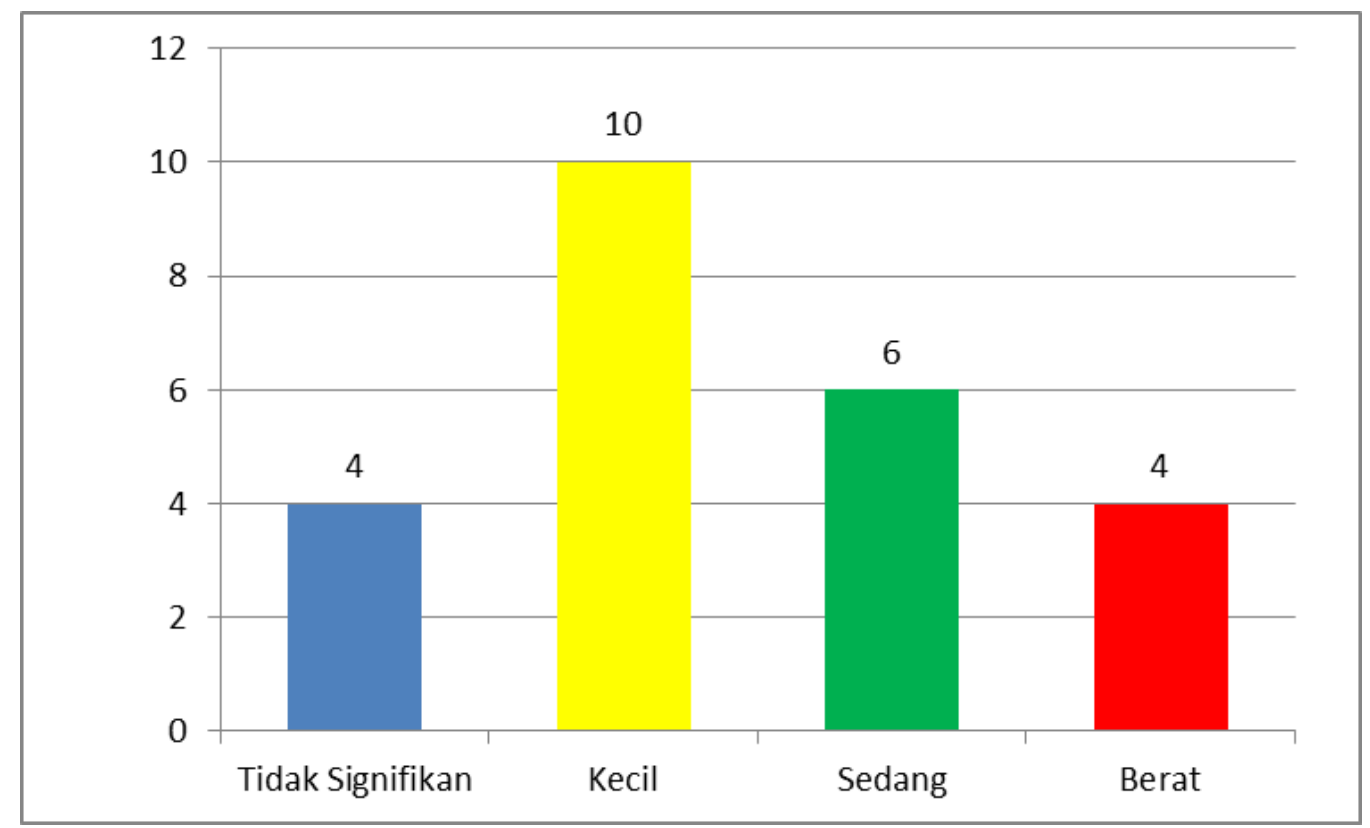

Gambar 2. Grafik Tingkat Keparahan (Severity) Risiko Bahaya

Grafik di atas menunjukkan bahwa tingkat keparahan risiko bahaya petugas pemadam kebakaran di Dinas Pemadam Kebakaran Kota Surakarta masuk dalam sebagian besar masuk dalam kriteri kecil sebanyak 10 (41,67\%) risiko bahaya. Namun demikian, bahaya yang dihadapi oleh petugas pemadam kebakaran tidaklah kecil. Masih banyak potensi bahaya yang masuk kateori tidak signifikan (4 atau 16,67\%), sedang (6 atau $25,00 \%$ ), dan berat (4 atau 16,67\%), sehingga petugas perlu memperhatikan alat-alat yang dipakai dan perlindungan diri yang dipakai selama bertugas.

Level risiko yang dihadapi petugas pemadam kebakaran di Dinas Pemadam Kebakaran Kota Surakarta dalam melaksanakan tugas memadamkan kebakaran dapat ditampilkan dalam matrik dan grafik berikut ini:

Tabel 1 Matrik Penilaian Risiko

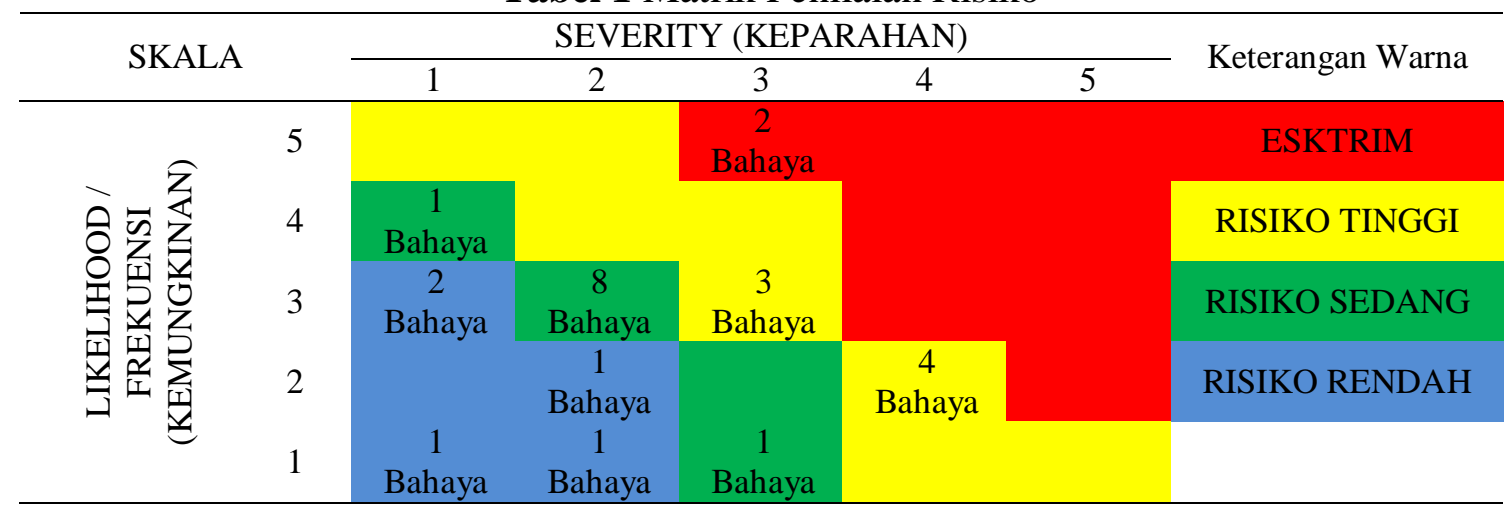




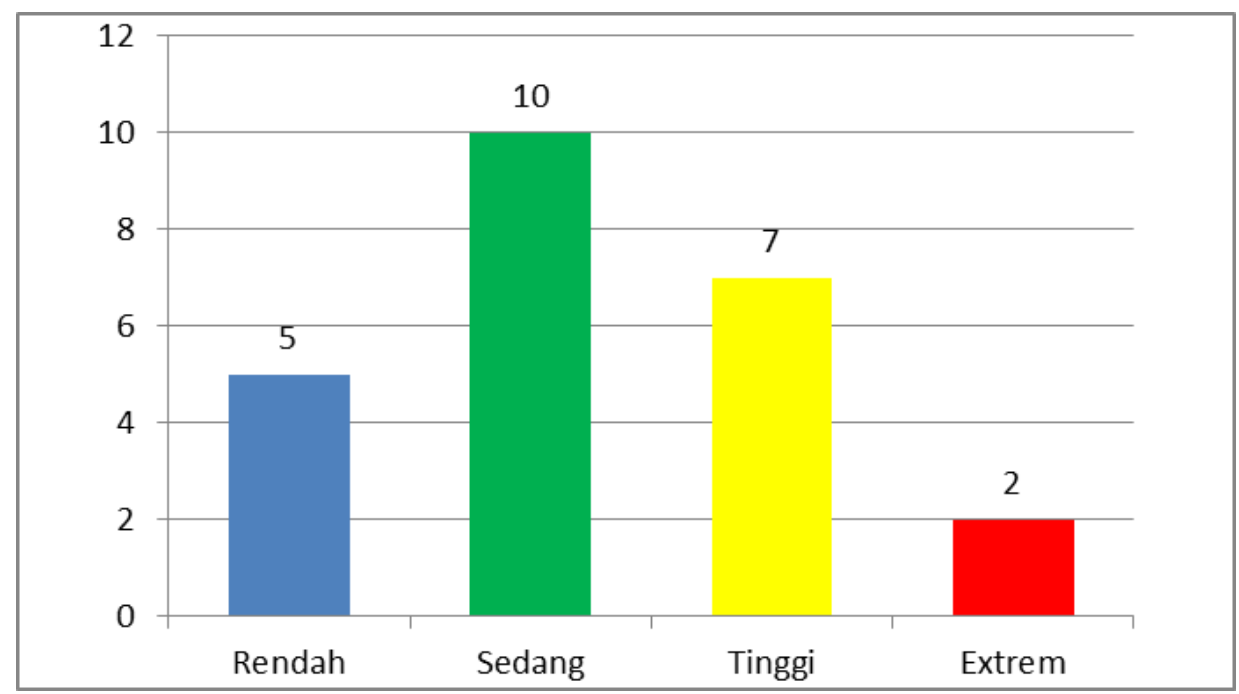

Gambar 3. Grafik Level Risiko Petugas Pemadam Kebakaran

Grafik tersebut di atas menunjukkan bahwa level risiko terbanyak adalah dalam kategori sedang yaitu sebanyak 10 (41,67\%), level risiko kategori tinggi sebanyak 7 $(29,17 \%)$, dan level risiko kategori Ekstrem sebanyak 2 (8,33\%). Sedangkan yang masuk ketegori rendah sebanyak $5(20,83 \%)$ potensi bahaya. Tingkat risiko yang harus mendapatkan perhatian adalah level tinggi dan ekstrem.

Berdasarkan hasil tersebut diketahui bahwa petugas tim kebakaran mempunyai risiko bahaya dalam bekerja dengan level rendah, sedang, tinggi dan ekstrem. Menurut Socrates (2013) risiko itu sendiri adalah perpaduan dari kemungkinan terjadinya kejadian berbahaya dengan keparahan dari cidera ataupun gangguan kesehatan yang disebabkan oleh kejadian. Sedangkan menurut Gunawan et al (2016) menyatakan bahwa risiko adalah kemungkinan terjadinya sesuatu yang menimbulkan kerugian yang besar atau tingginya risiko tersebut ditentukan oleh gabungan antara tingkat kemungkinan dan tingkat kerusakan akibat kejadian yang tidak diharapkan tersebut. Makin tinggi kemungkinan dan makin parah dampak kejadian, makin tinggi pula risiko yang dihadapi.

Berikut adalah potensi bahaya yang ditimbulkan dari pekerjaan petugas pemadam kebakaran :

\section{Kategori Risiko Ekstrem}

a. Suhu udara yang panas di lokasi kebakaran yang bisa mencapai $100^{\circ} \mathrm{C}$

b. Menghisap asap kebakaran yang mengandung zat-zat berbahaya antara lain Karbonmonoksida (CO), Karbondioksida $\left(\mathrm{CO}_{2}\right)$, Asam Sianida (HCN), Akrolin, Asam klorida $(\mathrm{HCl})$

\section{Kategori Risiko Tinggi}

a. Jatuh dari mobil karena kecepatan tinggi dan petugas duduk di tangki mobil pemadam kebakaran

b. Kecelakaan lalu lintas

c. Terkena reruntuhan bangunan

d. Terbakar

e. Ledakan bahan kimia (gas beracun)

f. Back draf (ledakan yang dihasilkan dari penyalaan serentak ketika suhu panas maksimal dan kurangnya asupan $\mathrm{O} 2$ ketika mendapatkan $\mathrm{O} 2$ terjadilah ledakan serentak masuk dalam kategori tinggi 
g. Terjatuh dari mobil karena kelelahan dan tingkat konsentrasi rendah

\section{Kategori Risiko Sedang}
a. Terpeleset saat naik ke atas mobil damkar dikarenakan terburu-buru
b. Kerumunan warga di lokasi kebakaran menganggu mobilitas petugas dan membahayakan warga sendiri
c. Terseret selang air yang memiliki tekanan tinggi yang tersambung dengan pompa air.
d. Tersengat aliran listrik
e. Mata perih terkena asap dan debu
f. Terjatuh atau terpeleset karena genangn air atau lokasi licin
g. Bekerja diketinggian ketika melakukan pemadaman menggunakan crane
h. Terkena benda tajam seperti kaca, besi, dan serpihan benda-benda lainnya
i. Peralatan kerja yang kurang sempurna
j. Kelelahan akibat proses pemadaman yang lama

\section{Kategori Risiko Rendah}
a. Jatuh dari tangga atau tiang pemadam kebakaran ketika mendapatkan panggilan darurat untuk melaksanakan pemadaman kebakaran
b. Jatuh dari tangga atau tiang pemadam kebakaran ketika mendapatkan panggilan darurat untuk melaksanakan pemadaman kebakaran
c. Pohon dan kabel listrik yang melintang jalan membahayakan petugas yang duduk di atas mobil
d. Terbelit selang air ketika mempersiapkan selang dari pompa ke lokasi kebakaran
e. Kebahisan air dalam tangki

Berdasarkan hasil penilaian risiko dengan menggunakan matrik HIRA pada pekerjaan profesi petugas kebakaran yang paling dominan ada di level risiko sedang. Risiko tersebut dapat kita kendalikan dengan menggunakan prinsip hirarki pengendalian bahaya yaitu subtitusi, eliminasi, engginering control, administrasi dan penggunaan APD. Pada upaya ini tindakan yang dapat kita lakukan untuk perbaikan diantaranya sebagai berikut: 1) Mempersiapkan mental dan fisik yang prima dalam rangka menghadapi tugas dan panggilan darurat/emergency. 2) Bekerja sama dengan pihak kepolisian untuk mengatur warga yang menyaksikan kebakaran. 3) Melakukan pelatihan secara rutin dan menjaga kebugaran petugas pemadam kebakaran. 4) Berkoordinasi dengan PLN untuk melakukan pemadaman listrik di sekitar lokasi kebakaran. 4) Perawatan dan pemeliharaan APD secara berkala. 5) Pengecekan peralatan secara rutin dan teliti. 6) Melengkapi petugas pemadam dengan kemampuan P3K yang memadai. 7) Memberikan waktu istirahat yang memadai.

\section{KESIMPULAN}

Level risiko terbanyak adalah dalam kategori sedang yaitu sebanyak $10(41,67 \%)$ potensi bahaya, level risiko kategori tinggi sebanyak 7 (29,17\%) potensi bahaya, dan 2 $(8,33 \%)$ potensi bahaya yang masuk kategori level risiko extrem. Sedangkan yang masuk ketegori rendah sebanyak $5(20,83 \%)$ potensi bahaya. Tingkat risiko yang harus mendapatkan perhatian adalah level tinggi dan ekstrem.

Jenis bahaya yang dihadapi petugas pemadam kebakaran terjadi ketika melaksanakan persiapan keberangkatan, berangkat ke lokasi kebakaran, penyiapan alat di 
lokasi kebakaran, proses pemadaman kebakaran, dan kembali ke markas setelah proses pemadaman selesai.

\section{SARAN}

Saran bagi dinas Pemadam Kebakaran Kota Surakarta harus memperbanyak jumlah baju pelindung diri untuk memadamkan kebakaran yang mengandung racun dan zat berbahaya. Dinas Pemadamkan Kebakaran Kota Surakarta agar mengusulkan kepada Pemerintah Kota Surakarta unntuk melaksanakan inventarisasi dan perbaikan terhadap sistem hidran yang ada di Kota Surakarta. Dinas Kebakaran Kota Surakarta agar selalu melakukan perawatan terhadap Alat Pelindung Diri khususnya baju tahan api, masker pelindung wajah, dan alat bantu pernafasan untuk mengindarkan petugas pemadam kebakaran dari paparan bahaya yang disebabkan suhu tinggi dan menghisap asap kebakaran. Petugas Dinas Pemadam Kebakaran Kota Surakarta harus selalu mematuhi prosedur kerja yang sudah ditetapkan untuk meminimalisir bahaya dan mencegah terjadinya risiko kecelakaan kerja.n Peneliti selanjutnya bisa melaksanakan penelitian mengenai risiko $\mathrm{K} 3$ petugas pemadam kebakaran menggunakan metode penilaian risiko yang lainnya, sehingga hasil penelitian dapat diperbandingkan untuk menghasilkan rekomendasi dan dijadikan dasar kebijakan bagi para pengambil keputusan.

\section{DAFTAR PUSTAKA}

Aini, A.N. 2016. Analisis Risiko Kerja dan Upaya Pengendalian Bahaya pada Petugas Pemadam Kebakasan di Dinas Pemadam Kebakaran Kota Semarang. Jurnal: Jurusan Keselamatan dan Kesehatan FKM UNDIP.

Andriyan, A. 2011. Perhitungan Nilai Kompensasi Atas Risiko Kerja Pemadam Kebakaran Dinas Kebakaran Kota Surabaya Melalui Pendekatan Manajemen Risiko. Skripsi. Mahasiswa Fakultas Teknik Institut Teknologi Sepuluh Nopember Surabaya.

Badan Perencanaan, Penelitian dan Pengembangan Daerah Kota Surakarta, 2018. Rencana Induk Sistem Proteksi Kebakaran (RISPK) Kota Surakarta.

Badan Standardisasi Nasional. 2018. Grand Desain Penerapan Manajemen Risiko di Badan Standardisasi Nasional 2018 - 2023.

Gunawan, F,A,. Lestari, Fatma., Subekti, Audist., \& Somad, Ismed. 2016. Manajemen Keselamatan Operasi. Bandung: PT. Gramedia Pustaka Utama.

Pratomo Setyadi dan Yola Furqaan Nanda. 2017. Karakteristik Penyebaran Api Ketika Terjadi Kebakaran Berbasis Metode FDS (Fire Dynamics Simulator) pada arkiran Sepeda Motor Kampus A Universitas Negeri Jakarta. Jurnal Konversi Energi dan Manufaktur UNJ, Edisi terbit II- Oktober 2017

Puspitasari, Nindya. 2010. Hazard identifikasi dan Risk Assesment dalam upaya megnurangi tingkat resiko dibagian produksi PT.Bina Guna Kimia Ungaran, Semarang. Skripsi.

Ramli,S. 2010. Manajemen Kebakaran. Dian Rakyat : Jakarta 
Rijanto, B. 2011. Pedoman Pencegahan Kecelakan Industri. Jakarta : Mitra Wacana Media.

Rizki, Kiki AR., Yuniar., \& Desrianty, Arie. 2014. Usulan perbaikan Sistem Menejemen Keselamatan dan Kesehatan Kerja (SMK3) menggunakan metode Hazard Identification and Risk Assesment (HIRA). Jurusan Teknik Industri Itenas Vol 2 No $2: 311-321$.

Sandy, Niko Eka, 2019. Penilaian Resiko Keselamatan Dan Kesehatan Kerja Pada Proses Reparasi di PT. Dok dan Perkapalan Surabaya. Seminar Nasional Kelautan XIV. "Implementasi Hasil Riset Sumber Daya Laut dan Pesisir Dalam Peningkatan Daya Saing Indonesia" Fakultas Teknik dan Ilmu Kelautan Universitas Hang Tuah, Surabaya 11 Juli 2019

Shafwani, R. 2012. Gambaran Risiko Pekerjaan Petugas Pemadam Kebakaran Dinas Pencegah Pemadam Kebakaran Dinas (DP2K) Kota Medan. Skripsi: Fakultas Kesehatan Masyarakat Universitas Sumatera Utara.

Socrates, Muhammad F. 2013. Analisis risiko keselamatan kerja dengan metode HIRARC (Hazard Identification, Risk Assesment and Risk Control) pada alat suspension Preheater bagian produksi di plant 6 dan 11 Field Citeureup PT Indocement Tunggal Prakarsa, tahun 2013.

Sugiyono. 2016. Metode Penelitian Kombinasi (Mixed Method). Bandung: Alfabeta.

Susihono, Wahyu., \& Akbar, Feni R. 2013.Penerapan Sistem Manajemen Keselamatan dan Kesehatan Kerja (K3) dan Identifikasi potensi bahaya kerja (Studi kasus: PT. LTX kota Cilegon-Banten). Spectrum Industri Vol 11 No 2 : 209-226. 